\title{
Microbial Diversity and Antibiotic Susceptibility Pattern of Bacteria Associated with Motorcycle Helmets
}

\author{
Sanjeep Sapkota $\mathbb{D}^{1,2,3}$ Sujan Khadka $\mathbb{D}^{1,},{ }^{1,3,4}$ Sanjib Adhikari $\mathbb{D}^{1},{ }^{1}$ Ashish Parajuli $\mathbb{D},{ }^{5}$ \\ Hemraj Kandel $\mathbb{D}^{6}{ }^{6}$ and Ramesh Sharma Regmi $\mathbb{D}^{1}$ \\ ${ }^{1}$ Department of Microbiology, Birendra Multiple Campus, Tribhuvan University, Bharatpur, Chitwan, Nepal \\ ${ }^{2}$ State Key Laboratory of Respiratory Disease, Guangzhou Institutes of Biomedicine and Health, Chinese Academy of Sciences, \\ Guangzhou, China \\ ${ }^{3}$ University of Chinese Academy of Sciences, Beijing, China \\ ${ }^{4}$ State Key Laboratory of Environmental Aquatic Chemistry, Research Center for Eco-Environmental Sciences, \\ Chinese Academy of Sciences, Beijing, China \\ ${ }^{5}$ Department of Microbiology, St. Xavier's College, Kathmandu, Nepal \\ ${ }^{6}$ Department of Biotechnology, National College, Kathmandu, Nepal
}

Correspondence should be addressed to Sanjib Adhikari; sanadh26@gmail.com

Received 13 June 2020; Accepted 15 October 2020; Published 29 October 2020

Academic Editor: Todd R. Callaway

Copyright (C) 2020 Sanjeep Sapkota et al. This is an open access article distributed under the Creative Commons Attribution License, which permits unrestricted use, distribution, and reproduction in any medium, provided the original work is properly cited.

\begin{abstract}
Background. Motorcycle helmets can serve as a potential vehicle for the transmission of pathogenic bacteria and fungi with serious health implications. The main aim of this study was to explore the microbial diversity associated with the motorcycle helmets and determine the antibiotic susceptibility profile of the bacterial isolates. Methods. A descriptive cross-sectional study was carried out among the teaching staffs of Birendra Multiple Campus, Bharatpur, Nepal. A total of 130 motorcycle helmets worn by the teaching staffs of the Birendra Multiple Campus, Bharatpur, were included in the study for microbiological investigations. Results. Of the total 130 motorcycle helmets analyzed, 392 bacteria and 346 fungi belonging to seven different genera were recovered. Staphylococcus aureus 89 (22.7\%) was the predominant bacteria followed by S. epidermidis 77 (19.6\%) and E. coli 54 (13.8\%), whereas Aspergillus niger 67 (19.4\%) was the predominant fungi followed by A. fumigatus 49 (14.2\%). Antibiotic susceptibility test was performed by the disc diffusion method for all the bacterial isolates. Tetracycline, gentamycin, and cotrimoxazole were the most effective antibiotics for Gram-positive isolates, whereas Gram-negative isolates were sensitive towards imipenem and ciprofloxacin. Of the total bacterial isolates, 153 (39.0\%) were multidrug-resistant (MDR), 10.4\% were extended-spectrum betalactamase (ESBL) producers, and 4.3\% were metallo-beta-lactamase (MBL) producers and, out of 89 isolates of Staphylococcus aureus, 30 (33.7\%) were detected as methicillin-resistant Staphylococcus aureus (MRSA). Conclusion. The findings suggest that motorcycle riders should follow good hygiene practices and regularly clean their helmets with suitable sterilants to avoid the risk of microbial contamination and reduce the associated risks.
\end{abstract}

\section{Introduction}

Transportation is essential to every human community and one of the easier means of transportation in most part of the world is the motorcycle. Motorcycles are fashionable means of transportation especially for short distances. Its frequent use and patronage is very high since it is quicker and convenient and can easily maneuver through the regular traffic jam and get to any destination, provided there is road facility [1]. Motorcycle helmets (MCHs) protect motorcyclists from serious head and brain injuries in the event of an accident [2]. However, constant handling and use of MCHs by different individuals could create a prime breeding ground for many microorganisms such as bacteria and mildews [3] and there is a possible transmission of pathogenic microorganisms as well as communicable diseases among users. 
Human skin, the human body's largest organ, is constantly in contact with environmental microorganisms and become readily colonized by certain microbial species. The adult human skin can hold about $10^{12} \mathrm{cfu} / \mathrm{ml}$ bacteria [4]. The colonization of potentially pathogenic organisms on inanimate objects like mobile phones, stethoscopes, currency notes, and computer keyboards has been reported as a potential vehicle for transmission of pathogenic organisms and important source of infections [5-8]. Some previous studies have revealed the presence of Staphylococcus aureus, Enterobacter aerogenes, Pseudomonas aeruginosa, Staphylococcus epidermidis, Escherichia coli, Bacillus spp., Aspergillus spp., Candida spp., Rhizopus spp., and Penicillium spp. from motorcycle helmets $[9,10]$. These normal microbiota can produce diseased condition if introduced into foreign locations or compromised hosts [11].

Antibiotics are a crucial line of defense against bacterial infections; however, bacteria resisting to antibiotics is a major public health concern $[12,13]$. Bacteria can be intrinsically resistant or acquire resistance to antibiotics through horizontal gene transfer of resistant genetic mobile elements and alteration in genetic composition [14]. There are increasing evidences of multidrug-resistant MRSA and ESBL producing bacterial isolates in inanimate objects $[8,15,16]$. In Nepal, there is paucity of information on potential hazards associated with common use of motorcycle helmets by different people. In context of country like ours, we do not find any research works conducted to reveal microbes that contaminate motorcycle helmets. A very few research works have been conducted even in the world regarding microbial contamination of motorcycle helmets. Since most of the organisms that contaminate the motorcycle helmets are capable of causing infections, this work certainly has health implications. Similarly, at the time when antibiotic resistance among nonclinical bacterial isolates is also increasing, understanding the AST pattern of the bacteria recovered from motorcycle helmets will be helpful in combating the battle with antimicrobial resistance.

\section{Methods}

2.1. Study Site. A descriptive cross-sectional study was carried out among the teaching staffs of Birendra Multiple Campus, Bharatpur, Nepal. Birendra Multiple Campus is a government-funded constituent campus of Tribhuvan University situated in Province No. 3. The campus has around 3000 students and 300 teaching and nonteaching staffs and more than $95 \%$ of the staffs in the campus rely on motorcycle as their daily mode of conveyance. A total of 130 teaching staffs were recruited in the study by random sampling method. Laboratory investigations were carried out in the Microbiology Laboratory of the campus. Data related to sociodemographic characteristics and personal hygiene practices were collected through interview method.

2.2. Collection and Processing of the Sample. The samples were collected from motorcycle helmets using two sterile swabs according to the method described by Sepehri et al.
[16]. Briefly, two sterile swabs moistened with sterile water were rotated over the inner surface of the helmets. The first swab was immediately streaked onto nutrient agar (NA) plates and MacConkey (MAC) agar plates, whereas the second swab was streaked on Potato Dextrose Agar (PDA) supplemented with chloramphenicol. NA and MAC agar plates were incubated aerobically at $37^{\circ} \mathrm{C}$ for $24 \mathrm{~h}$, while PDA plates were incubated at $28^{\circ} \mathrm{C}$ for 5-7 days. Distinct colonies were subcultured on NA until pure cultures were obtained.

2.3. Identification of Bacteria and Fungi. Identification of bacterial isolates was carried out based on their cultural, morphological, and biochemical characteristics [17]. Fungal mycelium was scraped off with the help of inoculating needle and teased out in a drop of lactophenol cotton blue on a clean and grease-free slide as described by Samson and Van Reenen-Hoekstra [18] and examined microscopically. Fungi were differentiated on the basis of cultural and morphological characteristics as reported by Samson et al. [19].

2.4. Antibiotic Susceptibility Test (AST) of the Bacterial Isolates. Antibiotic susceptibility tests were performed on Mueller-Hinton Agar (MHA) following Clinical and Laboratory Standards Institute (CLSI) guidelines [20]. The turbidity of the inoculums was adjusted to the equivalent turbidity of $0.5 \mathrm{McFarland}$ standards. Eighteen-hour cultures of test organisms incubated at $37^{\circ} \mathrm{C}$ were standardized by diluting to $0.5 \mathrm{McF}$ arland turbidity standards before spreading over the surface of Mueller-Hinton agar (MHA) and allowed to dry for 2-5 minutes. Using sterile tweezers, antimicrobial discs such as tetracycline $(30 \mu \mathrm{g})$, cloxacillin $(5 \mu \mathrm{g})$, erythromycin $(15 \mu \mathrm{g})$, amikacin $(30 \mu \mathrm{g})$, ciprofloxacin $(5 \mu \mathrm{g})$, cotrimoxazole $(25 \mu \mathrm{g})$, gentamycin $(10 \mu \mathrm{g})$, azithromycin $(15 \mu \mathrm{g})$, cefoxitin $(30 \mu \mathrm{g})$, and vancomycin $(30 \mu \mathrm{g})$ for Gram positive bacteria, and, for Gram negative bacteria, chloramphenicol $(30 \mu \mathrm{g})$, imipenem $(10 \mu \mathrm{g})$, amikacin $(30 \mu \mathrm{g})$, ciprofloxacin $(5 \mu \mathrm{g})$, azithromycin $(15 \mu \mathrm{g})$, nitrofurantoin $(300 \mu \mathrm{g})$, tetracycline $(30 \mu \mathrm{g})$, ceftazidime $(30 \mu \mathrm{g})$, gentamycin $(10 \mu \mathrm{g})$, and cotrimoxazole $(25 \mu \mathrm{g})$ were placed widely spaced aseptically on the surface of MHA plate. Tweezers were reflamed after application of each disc. The plates were then incubated at $37^{\circ} \mathrm{C}$ for $24 \mathrm{~h}$. Following incubation, diameter of inhibition zone (DIZ) was measured with a transparent ruler and the results were interpreted as resistant, intermediate, and sensitive according to the Clinical and Laboratory Standards Institute guidelines [20]. Multidrug-resistant (MDR) strain was identified as resistant to $\geq 3$ antimicrobial classes [21].

2.5. Screening of MRSA, ESBL, and MBL Producers. Cefoxitin $(30 \mu \mathrm{g})$ disc was used for screening of MRSA. Isolates showing inhibition zone $\leq 21 \mathrm{~mm}$ around cefoxitin disc were identified as MRSA strain.

Screening of ESBL producers was performed by using ceftazidime $(30 \mu \mathrm{g})$ and cefotaxime $(30 \mu \mathrm{g})$ discs. The zone of inhibition (ZOI) $\leq 22 \mathrm{~mm}$ for ceftazidime and $\leq 27 \mathrm{~mm}$ for cefotaxime was considered as a potential ESBL producer as 
recommended by Clinical and Laboratory Standards Institute (CLSI). Possible ESBL producers were subjected to combined disc test for phenotypic confirmation as recommended by CLSI [20]. The combination of ceftazidime and cefotaxime alone and in combination with clavulanic acid (CA) $(10 \mu \mathrm{g})$ was used for the confirmation of ESBL producing isolates. An increased ZOI of $\geq 5 \mathrm{~mm}$ for either antimicrobial agent tested in combination with CA versus its zone when tested alone was interpreted as positive for ESBL production.

Imipenem resistant Gram-negative isolates were selected for the detection of MBL production by disc potentiation method as previously described $[22,23]$. Briefly, bacterial isolates (adjusted to $0.5 \mathrm{McF}$ arland turbidity standards) were aseptically swabbed on Mueller-Hinton ( $\mathrm{MH}$ ) agar plates and standard antibiotic disks of imipenem $(10 \mu \mathrm{g})$ and meropenem $(10 \mu \mathrm{g})$ impregnated with EDTA $(1 \mu \mathrm{g})$ were aseptically placed on MH agar plates. Supplementary imipenem $(10 \mu \mathrm{g})$ and meropenem $(10 \mu \mathrm{g})$ disks without EDTA were also placed alongside the antibiotic disks impregnated with the chelating agent (EDTA) at a distance of $20 \mathrm{~mm}$ apart. All plates were then incubated at $30^{\circ} \mathrm{C}$ for $18-24 \mathrm{~h}$ and zone of inhibition were recorded after incubation. A difference of $\geq 7 \mathrm{~mm}$ between the zones of inhibition of any of the carbapenem disks with or without the chelating agents was considered as metallo $\beta$-lactamase production [23].

2.6. Quality Control. Reagents and media were frequently monitored for their expiry date and proper storage conditions. For the standardization of Kirby-Bauer test and performance testing of antibiotics and MHA, control strains of E. coli (ATCC 25922) and S. aureus (ATCC 25923) were used. Quality of sensitivity tests was maintained by maintaining the thickness of MHA at $4 \mathrm{~mm}$ and the $\mathrm{pH}$ at 7.2-7.4.

2.7. Data Management and Statistical Analysis. All the data obtained were analyzed using Statistical Package for Social Sciences (SPSS) software (Version 20.0). Chi-square test was used to determine the association between some selected variables and a $p$ value $\leq 0.05$ was considered to have significant association.

\section{Results}

3.1. Growth Pattern of Isolates. In the study, altogether 130 motorcycle helmets were analyzed, from which 392 bacteria and 346 fungi belonging to seven different genera were recovered. Out of them, 229 (58.0\%) were Gram positive bacteria belonging to three genera, Staphylococcus, Bacillus, and Micrococcus, whereas 163 (42.0\%) were Gram negative bacteria belonging to five genera, namely, Pseudomonas, E. coli, Enterobacter, Salmonella, and Klebsiella. Staphylococcus aureus $89(22.7 \%)$ was the predominant flora in Gram positive category, followed by S. epidermidis 77 (19.6\%), Bacillus spp. 44 (11.2\%), and Micrococcus spp. 19 (4.8\%), whereas, in Gram negative category, E. coli 54 (13.8\%) was the predominant flora followed by Enterobacter spp. 38 (9.7\%), Klebsiella spp. 33 (8.4\%), and equal number of
TABLE 1: Growth pattern of bacteria.

\begin{tabular}{lcc}
\hline SN & Name of organisms & Total cases (\%) \\
\hline 1 & Staphylococcus aureus & $89(22.7)$ \\
2 & Staphylococcus epidermidis & $77(19.6)$ \\
3 & Bacillus spp. & $44(11.2)$ \\
4 & Micrococcus spp. & $19(4.8)$ \\
5 & Pseudomonas aeruginosa & $19(4.8)$ \\
6 & E. coli & $54(13.8)$ \\
7 & Enterobacter aerogenes & $38(9.7)$ \\
8 & Salmonella spp. & $19(4.8)$ \\
9 & Klebsiella spp. & $33(8.4)$ \\
& Total & 392 \\
\hline
\end{tabular}

TABLE 2: Growth pattern of fungi.

\begin{tabular}{lcc}
\hline SN & Name of organisms & Total cases (\%) \\
\hline 1 & Candida albicans & $20(5.8)$ \\
2 & Aspergillus niger & $67(19.4)$ \\
3 & A. fumigates & $49(14.2)$ \\
4 & A. flavus & $45(13.0)$ \\
5 & Rhizopus spp. & $55(15.9)$ \\
6 & Mucor spp. & $34(9.8)$ \\
7 & Alternaria spp. & $19(5.5)$ \\
8 & Fusarium spp. & $36(10.4)$ \\
9 & Penicillium spp. & $21(6.1)$ \\
& Total & 346 \\
\hline
\end{tabular}

Pseudomonas aeruginosa and Salmonella spp. 19 (4.8\%) (Table 1).

Altogether, 346 fungi belonging to seven different genera were isolated from motorcycle helmets. Out of 346 fungi isolated, 20 (5.8\%) were yeast belonging to only one genus which was Candida albicans, whereas 326 (94.2\%) were molds belonging to 6 different genera such as Aspergillus, Rhizopus, Mucor, Alternaria, Fusarium, and Penicillium. Three species of Aspergillus were identified and they were A. niger, A. fumigatus, and A. flavus. Aspergillus niger 67(19.4\%) was the most predominant mold followed by A. fumigatus 49 (14.2\%). In contrast, Alternaria spp. 19 (5.5\%) were the least prevalent mold observed in the study (Table 2).

3.2. Distribution of Microbial Growth Based on Different Variables. Among 130 helmet samples, 115 were from males and 15 were from females. Helmet worn by male showed $73.9 \%$ bacterial and $65.2 \%$ fungal growth, while $80.0 \%$ bacterial and $66.7 \%$ fungal growth were recovered from the helmet worn by females. Helmets that were worn by the 40-60 age grouped people harbored more bacterial (77.8\%) and fungal (82.5\%) growth. Presence of microorganism in helmet was not associated with the gender and age of the rider $(p>0.05)$. Helmets that were worn for more than 3 years showed higher bacterial $(89.1 \%)$ and fungal $(80.4 \%)$ growth than helmets used for less than 3 years $(p<0.05)$. Helmets which were never washed or disinfected showed higher bacterial $(86.8 \%)$ and fungal (83.3\%) growth as compared to those helmet frequently washed or disinfected $(p<0.05)$. Shared helmet seemed to be more hazardous as 
TABLE 3: Distribution of microbial growth with different variables.

\begin{tabular}{|c|c|c|c|c|c|c|c|}
\hline \multirow{2}{*}{ Serial number } & \multirow{2}{*}{\multicolumn{2}{|c|}{ Attributes }} & \multirow{2}{*}{ Sample size } & \multicolumn{2}{|c|}{ Bacteria } & \multicolumn{2}{|c|}{ Fungus } \\
\hline & & & & Growth $N(\%)$ & $p$ value & Growth $N(\%)$ & $p$ value \\
\hline \multirow{2}{*}{1} & \multirow{2}{*}{ Gender } & Male & 115 & $85(73.9 \%)$ & \multirow{2}{*}{0.611} & $75(65.2 \%)$ & \multirow{2}{*}{0.912} \\
\hline & & Female & 15 & $12(80.0 \%)$ & & $10(66.7 \%)$ & \\
\hline \multirow{3}{*}{2} & \multirow{3}{*}{ Age-group } & $20-40$ & 28 & $19(67.9 \%)$ & \multirow{3}{*}{0.544} & $18(64.3 \%)$ & \multirow{3}{*}{0.861} \\
\hline & & $40-60$ & 81 & $63(77.8 \%)$ & & $52(82.5 \%)$ & \\
\hline & & $60+$ & 21 & $15(71.4 \%)$ & & $15(71.4 \%)$ & \\
\hline \multirow{3}{*}{3} & \multirow{3}{*}{ Length of helmet used } & $<1 \mathrm{yrs}$ & 25 & $15(60.0 \%)$ & \multirow{3}{*}{$0.001^{*}$} & $13(52.0 \%)$ & \multirow{3}{*}{$0.023^{*}$} \\
\hline & & $1-3$ yrs & 59 & $36(61.1 \%)$ & & $35(59.3 \%)$ & \\
\hline & & $>3 \mathrm{yrs}$ & 46 & $41(89.1 \%)$ & & $37(83.4 \%)$ & \\
\hline \multirow{3}{*}{4} & \multirow{3}{*}{ Hygienic practice } & Disinfected & 5 & $1(20.0 \%)$ & \multirow{3}{*}{$0.001^{*}$} & $1(20.0 \%)$ & \multirow{3}{*}{$0.022^{*}$} \\
\hline & & Washed & 42 & $24(57.1 \%)$ & & $24(57.1 \%)$ & \\
\hline & & None & 83 & $72(86.7 \%)$ & & $60(83.3 \%)$ & \\
\hline \multirow{2}{*}{5} & \multirow{2}{*}{ Sharing of helmet } & Shared & 96 & $76(79.2 \%)$ & \multirow{2}{*}{$0.045^{*}$} & $69(71.9 \%)$ & \multirow{2}{*}{$0.008^{*}$} \\
\hline & & Not shared & 34 & $21(61.8 \%)$ & & $16(47.0 \%)$ & \\
\hline
\end{tabular}

*Significant at $5 \%$ level of significance.

TABLE 4: Antibiotic susceptibility pattern of Gram-positive isolates.

\begin{tabular}{|c|c|c|c|c|c|c|c|c|c|}
\hline \multirow{3}{*}{ Serial number } & \multirow{3}{*}{ Antibiotics used } & \multicolumn{8}{|c|}{ Susceptibility pattern } \\
\hline & & \multicolumn{2}{|c|}{ S. aureus $(n=89)$} & \multicolumn{2}{|c|}{$\begin{array}{l}\text { S. epidermidis } \\
(n=77)\end{array}$} & \multicolumn{2}{|c|}{$\begin{array}{l}\text { Bacillus spp. } \\
\quad(n=44)\end{array}$} & \multicolumn{2}{|c|}{$\begin{array}{c}\text { Micrococcus spp. } \\
(n=19)\end{array}$} \\
\hline & & S (\%) & $\mathrm{R}(\%)$ & S (\%) & $\mathrm{R}(\%)$ & S (\%) & $\mathrm{R}(\%)$ & S (\%) & $\mathrm{R}(\%)$ \\
\hline 1 & Tetracycline & 88.8 & 11.2 & 85.7 & 14.3 & 88.6 & 11.4 & 84.2 & 15.8 \\
\hline 2 & Cloxacillin & 91.0 & 9.0 & 89.9 & 10.1 & 40.9 & 59.1 & 73.7 & 26.3 \\
\hline 3 & Erythromycin & 57.3 & 42.7 & 66.2 & 33.8 & 34.1 & 65.9 & 36.8 & 63.2 \\
\hline 4 & Gentamicin & 94.4 & 5.6 & 100.0 & 0.0 & 84.1 & 15.9 & 78.9 & 21.1 \\
\hline 5 & Amikacin & 82.0 & 18.0 & 85.7 & 14.3 & 44.7 & 52.3 & 68.4 & 31.6 \\
\hline 6 & Cotrimoxazole & 89.9 & 10.1 & 92.2 & 7.8 & 63.6 & 36.4 & 63.2 & 36.8 \\
\hline 7 & Ciprofloxacin & 77.5 & 22.5 & 90.9 & 9.1 & 93.2 & 6.8 & 68.4 & 31.6 \\
\hline 8 & Azithromycin & 76.0 & 24.0 & 83.1 & 16.9 & 75.0 & 25.0 & 73.7 & 26.3 \\
\hline 9 & Cefoxitin & 66.3 & 33.7 & 79.2 & 20.8 & 79.5 & 20.5 & 47.4 & 52.6 \\
\hline 10 & Vancomycin & 88.8 & 11.2 & 88.3 & 11.7 & 65.9 & 34.1 & 63.2 & 36.8 \\
\hline
\end{tabular}

$S=$ sensitive; $R=$ resistant.

$79.2 \%$ bacterial and $71.88 \%$ of fungal growth was recorded $(p<0.05)$ (Table 3).

3.3. Antibiotic Susceptibility Pattern of Gram-Positive Isolates. In vitro drug susceptibility was performed for all Gram positive isolates by Modified Kirby Bauer Disc Diffusion method. Tetracycline, gentamicin, and cotrimoxazole were the most effective antibiotics for Gram positive isolates. Staphylococcus epidermidis showed $100 \%$ sensitivity towards gentamicin. High level of resistance was shown by the Bacillus spp. towards cloxacillin (59.1\%), erythromycin (65.9\%), and amikacin (52.3\%). On the other hand, $\mathrm{Mi}$ crococcus spp. showed $63.2 \%$ and $52.6 \%$ resistance towards erythromycin and cefoxitin, respectively. Among 89 isolates of Staphylococcus aureus, 30 (33.7\%) were detected as MRSA (Table 4).

3.4. Antibiotic Susceptibility Pattern of Gram-Negative Isolates. Gram negative isolates were sensitive towards imipenem and ciprofloxacin. Klebsiella spp. and Salmonella spp. were $100.0 \%$ sensitive to gentamicin and imipenem, respectively. The majority of Gram negative isolates showed high rate of resistance to cotrimoxazole and tetracycline. High level of resistance was shown by Pseudomonas aeruginosa towards nitrofurantoin (57.9\%), tetracycline (63.2\%), and gentamicin (73.7\%). Among 392 bacterial isolates, 153 (39.0\%) were multidrug-resistant (Table 5).

3.5. Frequency of ESBL and MBL Producers. All Gram negative isolates were further tested for ESBL and MBL activity. The overall percentage for ESBL and MBL producers was $10.4 \%$ and $4.3 \%$, respectively. High prevalence of ESBL producers was seen among Pseudomonas aeruginosa (21.0\%) and Klebsiella spp. (15.1\%), whereas none of the Enterobacter aerogenes isolates was detected as ESBL producers. Pseudomonas aeruginosa (10.5\%), Klebsiella spp. (6.1\%), and E. coli (5.6\%) were detected as MBL producers (Table 6).

\section{Discussion}

Microbiology standards in hygiene are prerequisite for a health living. It is not uncommon however to observe shift in hygienic practices that deviate from standards in developing 
TABLE 5: Antibiotic susceptibility pattern of Gram-negative isolates.

\begin{tabular}{|c|c|c|c|c|c|c|c|c|c|c|c|}
\hline \multirow{3}{*}{ Serial number } & \multirow{3}{*}{ Antibiotics used } & \multicolumn{10}{|c|}{ Susceptibility pattern } \\
\hline & & \multicolumn{2}{|c|}{ E. $\operatorname{coli}(n=54)$} & \multicolumn{2}{|c|}{$\begin{array}{l}\text { Klebsiella spp. } \\
\quad(n=33)\end{array}$} & \multicolumn{2}{|c|}{$\begin{array}{l}\text { P. aeruginosa } \\
(n=19)\end{array}$} & \multicolumn{2}{|c|}{$\begin{array}{l}\text { Salmonella spp. } \\
\qquad(n=19)\end{array}$} & \multicolumn{2}{|c|}{$\begin{array}{c}\text { Enterobacter } \\
\text { aerogenes } \\
(n=38)\end{array}$} \\
\hline & & S (\%) & $\mathrm{R}(\%)$ & S (\%) & $\mathrm{R}(\%)$ & S (\%) & $\mathrm{R}(\%)$ & S (\%) & $\mathrm{R}(\%)$ & S (\%) & $\mathrm{R}(\%)$ \\
\hline 1 & Chloramphenicol & 66.7 & 33.3 & 84.8 & 15.2 & 89.5 & 10.5 & 78.9 & 21.1 & 94.7 & 5.3 \\
\hline 2 & Imipenem & 88.9 & 11.1 & 87.9 & 12.1 & 84.2 & 15.8 & 100.0 & 0.0 & 97.4 & 2.6 \\
\hline 3 & Amikacin & 92.6 & 7.4 & 93.9 & 6.1 & 63.2 & 36.8 & 89.5 & 10.5 & 78.9 & 21.1 \\
\hline 4 & Ciprofloxacin & 83.3 & 16.7 & 75.8 & 24.2 & 78.9 & 21.1 & 73.7 & 26.3 & 86.8 & 13.2 \\
\hline 5 & Azithromycin & 75.9 & 24.1 & 45.5 & 54.5 & 89.5 & 10.5 & 89.5 & 10.5 & 78.9 & 21.1 \\
\hline 6 & Nitrofurantoin & 53.7 & 46.3 & 39.4 & 60.6 & 42.1 & 57.9 & 42.1 & 57.9 & 44.7 & 55.3 \\
\hline 7 & Tetracycline & 72.2 & 27.8 & 84.8 & 15.2 & 36.8 & 63.2 & 68.4 & 31.6 & 52.6 & 47.4 \\
\hline 8 & Ceftazidime & 85.2 & 14.8 & 81.8 & 18.2 & 68.4 & 31.6 & 94.7 & 5.3 & 94.7 & 5.3 \\
\hline 9 & Gentamicin & 98.1 & 1.9 & 100.0 & 0.0 & 26.3 & 73.7 & 52.6 & 47.4 & 97.4 & 2.6 \\
\hline 10 & Cotrimoxazole & 59.3 & 40.7 & 60.6 & 39.4 & 78.9 & 21.1 & 47.4 & 52.6 & 34.2 & 65.8 \\
\hline
\end{tabular}

$S=$ sensitive; $R=$ resistant.

TABLE 6: Frequency of ESBL and MBL producing Gram negative isolates.

\begin{tabular}{lcccc}
\hline Serial number & Isolates & Total number of isolates & ESBL producers $n(\%)$ & MBL producers $n(\%)$ \\
\hline 1 & E. coli & 54 & $7(13.0)$ & $3(5.6)$ \\
2 & Klebsiella spp. & 33 & $5(15.1)$ & $2(6.1)$ \\
3 & Pseudomonas aeruginosa & 19 & $4(21.0)$ & $2(10.5)$ \\
4 & Salmonella spp. & 19 & $1(5.3)$ & 0 \\
5 & Enterobacter aerogenes & 38 & 0 & 0 \\
& Total & 163 & $17(10.4)$ & $7(4.3)$ \\
\hline
\end{tabular}

and developed countries. Motorcycle helmets have been identified as a possible vehicle for the transmission of pathogenic bacteria and fungi; so, efforts to minimize transfer of such agents through good hygiene practice (GHP) are essential to maintain good health [10].

In this study, the number of bacteria isolated (392) was higher than the number of fungi (346). The variety of bacterial and fungal genera obtained in the study is similar to the works done previously in Lagos metropolis, Nigeria $[9,10,24]$. Additionally, Micrococcus spp. was isolated in the present study. Similarly, apart from the work in Nigeria, two new genera of the fungi Mucor and Alternaria were isolated in this study. Staphylococcus aureus, the predominant flora in our study, is a normal flora of skin but it is an opportunistic pathogen as it is known to cause boils, abscesses, wound infections, toxic shock syndrome, pneumonia, and other diseases $[25,26]$. Similarly, Staphylococcus epidermidis is also a skin commensal flora but is also responsible for endocarditis and infections of patients with lowered immunity [27]. Their presence indicates that the use and sharing of motorcycle helmets can lead to transmission of serious skin infections. The presence of coliforms like E. coli and Enterobacter aerogenes indicates possible fecal contamination [28]. Its implication is that handling of motorcycle helmets could be a potential source of food poisoning when infected hands are used in eating and food preparation without proper hygiene of hand washing [26]. Aspergillus fumigatus, a common fungus in the environment, is responsible for allergies and has also been linked to severe asthma, sinusitis, and pulmonary aspergillosis [29].
Moreover, Candida species are the commensal flora of gastrointestinal tract, respiratory tract, and vagina and cause candidiasis and oral thrust [26].

A higher proportion of bacterial as well as fungal growth was reported from helmets worn by females and $40-60$ age grouped riders $(p>0.05)$. This result is different from the study done in Islamic University of Gaza which reported the rate of incidence of contamination of mobile phones held by females was lower than that of male counterparts [30]. Usually, females keep longer nails which can directly transmit the microorganisms to the helmets [31]. Helmets that have been used for more than 3 years showed higher incidence of microbial growth. Helmets used for longer time period resulted in the attachment of microbes on the surface which results in the formation of biofilms and they are hard to remove [32]. Disinfected helmets showed the lower rate of microbial growth than that of nondisinfected helmets $(p<0.05)$. This result was in line with a study done in Nepal which showed the lower rate of microbial growth in disinfected mobiles phones [8]. Disinfection processes can actively kill the microbes from inanimate surfaces that lead to the reduction of microbial count $[33,34]$. Moreover, shared helmet was found to have more bacterial as well as fungal growth than that of unshared one $(p<0.05)$. It is imperative that sharing of the inanimate objects facilitates the transfer of microbes from one surface to another. On microbial susceptibility testing, tetracycline, gentamicin and cotrimoxazole were the most effective antibiotics for Gram positive isolates, whereas Gram negative isolates 
showed sensitivity towards imipenem and ciprofloxacin. This was in contrary with the study done in Nigeria which showed bacterial sensitivity to oflaxacin was the highest [9]. The rate of antibiotic resistance is increasing rapidly and poses grave economical and medical implications such as high morbidity and mortality [35]. Majority of the Salmonella spp. and Pseudomonas aeruginosa were found to be resistant to gentamicin. Bacterial resistance to gentamicin has been earlier reported and the resistance evolution mechanism is attributable to mobile genetic elements [36]. The emergence of MRSA, ESBL, and MBL producing bacteria has become a serious concern. This study reported $33.7 \%$ of the Staphylococcus aureus as MRSA which was in tune with the previous study done in nonclinical samples $[8,33,37]$. ESBLs are plasmid mediated TEM and SHV-type enzymes capable of hydrolysing penicillins, broad-spectrum cephalosporins, and monobactams [38]. Among 163 Gram negative isolates, 10.4\% ESBL and 4.3\% MBL producers were reported. In a study from Iran on mobile phones, ESBL was reported in $40 \%$ of the isolates. However, some fewer studies did not report a single case of ESBL and MBL producers [39, 40].

\section{Conclusion}

The current study shows that motor cycle helmets could serve as a potential vehicle for transmission of drug-resistant bacteria and fungi with serious health implications. Hence, good hygiene practice (GHP) should be followed by the motorcycle riders with regular cleaning of the helmets by suitable sterilants in order to reduce the occurrence of microbial contamination and transmission of microbes via helmets.

\section{Data Availability}

The data used to support the findings of this study are included within the article.

\section{Conflicts of Interest}

The authors declare that they have no conflicts of interest.

\section{Authors' Contributions}

SA led study design, planning, implementation, and interpretation of findings and prepared the first draft of the manuscript. SS, SK, AP, HK, and RSR did the laboratory analyses. SA, SS, and SK reviewed the manuscript and made the final draft. All the authors read and approved the final manuscript.

\section{Acknowledgments}

The authors are grateful to all the teaching staffs who contributed by being enrolled in the sampling stages of the research work. The study was supported by the Research Management Committee of Birendra Multiple Campus.

\section{References}

[1] T. Banjo, E. Nwaze, and G. Aja, "Perceptions and attitudinal disposition of commercial motorcycle passengers towards helmet use in a Nigerian metropolitan suburb," Acta SATECH, vol. 4, pp. 74-80, 2011.

[2] B. Liu, R. Ivers, R. Norton, S. Blows, and S. Lo, "Helmets for preventing injury in motorcycle riders," Cochrane Database of Systematic Reviews, vol. 4, 2003.

[3] R. Roth and W. Jenner, "Microbial ecology of the skin," Annual Review of Microbiology, vol. 42, pp. 42-43, 1998.

[4] P. A. Mackowiak, "The normal microbial flora," New England Journal of Medicine, vol. 307, no. 2, p. 83, 1982.

[5] A. M. Whittington, G. Whitlow, D. Hewson, C. Thomas, and S. J. Brett, "Bacterial contamination of stethoscopes on the intensive care unit," Anaesthesia, vol. 64, no. 6, pp. 620-624, 2009.

[6] D. Tagoe, L. Adams, and V. Kangah, "Antibiotic resistant bacterial contamination of the Ghanaian currency note: a potential health problem," Journal of Microbiology and Biotechnology Research, vol. 1, pp. 37-44, 2011.

[7] M. Schultz, J. Gill, S. Zubairi, R. Huber, and F. Gordin, "Bacterial contamination of computer keyboards in a teaching hospital," Infection Control \& Hospital Epidemiology, vol. 23, pp. 274-276, 2003.

[8] S. Khadka, S. Adhikari, S. Sapkota, and P. Shrestha, "Methicillin-resistant Staphylococcus aureus associated with mobile phones," SOJ Microbiology \& Infectious Diseases, vol. 6, no. 1, pp. 1-6, 2018.

[9] E. Obinna, A. Leonard, E. Faustina et al., "Antibiotics susceptibility pattern and plasmid profile of bacteria isolated from public motorcycle helmets," American journal of microbiological research, vol. 4, pp. 126-131, 2016.

[10] L. Adamu, B. Edeghagba, F. Olatomi, O. Ezeokoli, and A. Elijah, "Microorganisms associated with commercial motorcycle helmets in Lagos metropolis," Journal of Microbiology, Biotechnology and Food Sciences, vol. 1, pp. 11791188, 2012.

[11] T. Ekrakene and C. Igeleke, "Micro-organism associated with public mobile phone along benin, sapele expressway," Journals Applied scientific research, vol. 3, pp. 2009-2012, 2007.

[12] G. Dantas, M. O. Sommer, R. D. Oluwasegun, and G. M. Church, "Bacteria subsisting on antibiotics," Science, vol. 320, pp. 100-103, 2008.

[13] D. M. Livermore, "Has the era of untreatable infections arrived?" Journal of Antimicrob Chemother, vol. 64, pp. 129-136, 2009.

[14] B. H. Normark and S. Normark, "Evolution and spread of antibiotic resistance," Journal of Internal Medicine, vol. 252, no. 2, pp. 91-106, 2002.

[15] D. Jeyakumari, S. Nagajothi, P. Kumar, R. Ilayaperumal, and G. Vigneshwaran, "Bacterial colonization of stethoscope used in the tertiary care teaching hospital: a potential source of nosocomial infection," International Journal of Research in Medical Sciences, vol. 5, pp. 142-145, 2017.

[16] G. Sepehri, N. Talebizadeh, A. Mirzazadeh, T. R. Mir-shekari, and E. Sepehri, "Bacterial contamination and resistance to commonly used antimicrobials of healthcare workers' mobile phones in teaching hospitals, Kerman, Iran," American Journal of Applied Sciences, vol. 6, p. 206, 2009.

[17] B. A. Forbes and D. F. W. A. Sahm, Diagnostic Microbiology, St Louis, St. Louis, MO, USA, 2007.

[18] R. A. Samson and E. S. Van Reenen-Hoekstra, Introduction to Foodborne Fungi, Central bureau voor Schimmelcultures 
(CBS), Institute of the Royal Netherlands Academy of Arts and Sciences, Baarn, Delft, Netherlands, 3 edition, 1988.

[19] R. A. Samson, E. S. Hoekstra, and C. A. N. Van Oorschot, Introduction to Foodborne Fungi, Academy Arts Science, Baarn, Delft, Netherlands, 2 edition, 1984.

[20] Clinical Laboratory Standards Institute (CLSI), Performance Standards for Antimicrobial Susceptibility Testing. 24th Informational Suppl (M100-S28), Clinical Laboratory Standards Institute (CLSI), Wayne, MD, USA, 2016.

[21] A.-P. Magiorakos, A. Srinivasan, R. B. Carey et al., "Multidrug-resistant, extensively drug-resistant and pandrug-resistant bacteria: an international expert proposal for interim standard definitions for acquired resistance," Clinical Microbiology and Infection, vol. 18, no. 3, pp. 268-281, 2012.

[22] A. Varaiya, N. Kulkarni, M. Kulkarni, P. Bhalekar, and J. Dogra, "Incidence of metallo beta lactamases producing Pseudomonas aeruginosa in ICU patients," Indian Journal of Medical Research, vol. 127, pp. 398-402, 2008.

[23] P. C. Ejikeugwu, C. M. Ugwu, I. R. Iroha, P. Eze, T. Gugu, and C. Esimone, "Phenotypic detection of metallo- $\beta$-lactamase enzyme in enugu, southeast Nigeria," American Journal of Biological, Chemical and Pharmaceutical Sciences, vol. 2, pp. 1-6, 2014

[24] W. Nigatu, N. S. Fabiola, I. J. Flora et al., "Comparative study on the level of bacteriological contamination of automatic teller machines, public toilets and public transport commercial motorcycle crash helmets in Kigali City, Rwanda," East African Medical Journal, vol. 91, pp. 467-476, 2014.

[25] G. F. Brooks, S. J. Butel, and S. A. Moses, Medical Microbiology, Lange Medical Books/McGraw Hill Medical Publishing Divisions, New York, NY, USA, 2007.

[26] M. Yusha'u, M. Bello, and H. Sule, "Isolation of bacteria and fungi from personal and public mobile cellphones: a case study of Bayero University, Kano (Old Campus)," International Journal of Biomedical and Healthcare Science, vol. 6, pp. 97-102, 2010.

[27] A. Piette and G. Verschraegen, "Role of coagulase-negative staphylococci in human disease," Veterinary Microbiology, vol. 134, no. 1-2, pp. 45-54, 2009.

[28] S. Ishii and M. J. Sadowsky, "Escherichia coli in the environment: implications for water quality and human health," Microbes and Environments, vol. 23, no. 2, pp. 101-108, 2008.

[29] J. Willey, L. Sherwood, and C. Woolverton, Prescotts Microbiology, McGraw-Hill, New York, NY, USA, 8 edition, 2011.

[30] A. Elmanama, I. Hassona, A. Marouf, G. Alshaer, and E. Ghanima, "Microbial load of touch screen mobile phones used by university students and healthcare staff," Journal of the Arab American University, vol. 1, no. 1, pp. 1-18, 2015.

[31] S. H. Al-Zahrani, "Detection of antibiotic resistant Staphylococcus aureus among male carriers in jeddah Sites," Natural science, vol. 10, 2012.

[32] G. O'Toole, H. B. Kaplan, and R. Kolter, "Biofilm formation as microbial development," Annual Review of Microbiology, vol. 54, pp. 49-79, 2000.

[33] M. A. Merlin, M. L. Wong, P. W. Pryor et al., "Prevalence of methicillin-ResistantStaphylococcus aureuson the stethoscopes of emergency medical services providers," Prehospital Emergency Care, vol. 13, no. 1, pp. 71-74, 2009.

[34] S. Sapkota, S. Adhikari, A. Pandey et al., "Multi-drug resistant extended-spectrum beta-lactamase producing E. coli and Salmonella on raw vegetable salads served at hotels and restaurants in Bharatpur, Nepal," BMC Research Notes, vol. 12, no. 1, pp. 1-6, 2019.
[35] J. McGowan, "Economic impact of antimicrobial resistance," Emerging Infectious Diseases, vol. 7, pp. 286-292, 2001.

[36] H. Heuer, E. W. E. Krögerrecklenfort, S. Egan et al., "Gentamicin resistance genes in environmental bacteria: prevalence and transfer," FEMS Microbiology, vol. 42, pp. 289-302, 2007.

[37] R. Neel, "Multidrug resistance of isolates of methicillin resistant Staphylococcus aureus (MRSA) in paper currency notes from restaurants and hotels in Lusaka in Zambia," International Journal of Pharmaceutical Sciences, vol. 5, pp. 363-366, 2012.

[38] M. E. Rupp and P. D. Fey, "Extended spectrum?-lactamase (ESBL)-producing enterobacteriaceae," Drugs, vol. 63, no. 4, pp. 353-365, 2003.

[39] S. Siddiqui, H. Jamal, S. Kotgire, and U. Afreen, "Bacterial contamination of mobile phones of healthcare workers at a tertiary care hospital," ndian Journal of Applied Research, vol. 5, pp. 732-735, 2017.

[40] R. Rana, S. Joshi, S. Lakhani, M. Kaur, and P. Patel, "Cell phones-homes for microbes," International Journal of Biological and Medical Research, vol. 4, pp. 3403-3406, 2013. 